\title{
The Role of Nitrobenzoic Acid Derivatives on Callus Induction and Plant Regeneration in Paulownia Shan Tong
}

\author{
Roxana LUCA ${ }^{1 *}$, Manuela CRISAN ${ }^{2}$, Dorica BOTAU ${ }^{1}$ \\ ${ }^{\mathbf{1} B U A S V M}$ - Banat's University of Agricultural Sciences and Veterinary Medicine „King Michael I of \\ Romania",Timisoara, Romania. \\ ${ }^{2}$ Institute of Chemistry Timisoara of Romanian Academy, 24 Mihai Viteazul Blvd, 300223, Timisoara, \\ Romania \\ * corresponding author: roxana.luca@publicparc.com
}

Bulletin UASVM Animal Science and Biotechnologies 73(2)/ 2016

Print ISSN 1843-5262; Electronic ISSN 1843-536X

DOI:10.15835/buasvmcn-asb: 12218

\begin{abstract}
Paulownia is a multipurpose tree species with a rapid growth which is cultivated in several temperate zones worldwide for its economic importance. The present study was undertaken to investigate the effects of different alkanolamine salts of 4-nitrobenzoic acid on in vitro callus induction and plant regenerating in Paulownia shan tong. The alkanolamine salts, namely methylethanolamine 4-nitrobenzoate (4- $\mathrm{NO}_{2} \mathrm{BA}$ MMEA), diethanolamine 4-nitrobenzoate (4- $\mathrm{NO}_{2} \mathrm{BA}$ DEA) and triethanolamine 4-nitrobenzoate (4- $\mathrm{NO}_{2} \mathrm{BA}$ TEA) are new synthesized compounds with biological activity and low toxicity. The influence of title compounds on sprout length, number of internodes, number of leaves and number of ramifications has been studied at two different concentrations: 1 $\mathrm{mg} / \mathrm{L}$ respectively $0.5 \mathrm{mg} / \mathrm{L}$. The experimental data show that new tested compounds have a better growth effect on plant vegetable parties in report to control, the most eloquent results being obtained for 4- $\mathrm{NO}_{2} \mathrm{BA}$ MMEA. For callus induction 2,4-D (2,4-dichlorophenoxyacetic acid) hormonal balances were attempted and the development of callus was examined at two different concentrations. An induced callus development was observed regarding callus dimensions for all explants inoculated on culture medium supplemented with 2,4-D.
\end{abstract}

Keyword: Paulownia; in vitro culture; callus; alkanolamine salts of 4-nitrobenzoic acid

\section{INTRODUCTION}

The genus Paulownia, one of the fastest growing and hardwood tree in the world, includes several species and natural hybrids that are native to China. The trees reach impressive dimensions in the first years of life exceeding 5 meters in height (Yadav et al., 2013). The wood is strong, yet light weight, making it ideal for musical instruments, chests, boxes, furniture, lightweight skis, doors and windows, delivery containers (Akyildiz and Kol, 2010; Kiaei, 2012). Another usage of Paulownia wood is making paper pulp that is of higher quality comparable to Eucalyptus (Feria, et al., 2013). Due to the mentioned qualities, Paulownia species are among the most important forestry crops in the world. In the last decade, Paulownia becomes an important culture also in Romania where about 200 ha are annually cultivated (Stiriagricole. ro, 2015), being used acclimatized hybrids for specific weather conditions. Thus, Paulownia shan tong, a new paulownia variety, attracts attention by fast growing rate, strong resistance to disease and insect pest, strong resistance to drought and cold, large timber output, good material quality, strong renewal ability, comparatively with other Paulownia species (e.g. elongata).

Paulownia can be propagated through seeds, stem cutting roots or in vitro by tissue culture 
(Burger, 1985). It was established that propagation by seeds or early seedling growth is slower and difficult than vegetative propagated plants produced from root and shoot cutting or rooted shoots from tissue culture. In vitro propagation technique provides healthy, homogeneous planting stock for a forestation and woody biomass production of Paulownia. Mass multiplication of Paulownia elongata through axillary shoots and nodal culture was reported (Bergmann and Moon, 1997) and also in vitro propagation of Paulownia tomentosa through shoot bud regeneration (Rao, Goh and Kumar, 1996).

Plant growth regulators play an essential role in micropropagation of plants, being commonly used in conditioning media for increasing multiplication rate and development of new plantlets. Among them, the auxins are the best studied inducers for somatic embryogenesis, an important pathway for plantlet regeneration. The synthetic auxin 2,4-D is frequently used to induce somatic embryogenesis in many plant species (Mordhorst et al., 1998; Zimmerman 1993). Beside auxins, gibberellin and cytokinin may increase the multiplication rate in some plants. Thus, for Paulownia tomentosa and fortunei species, a better growth rate was observed when the culture medium was prepared with 6-benzylaminopurine (BAP) and gibberellic acid (GA3) (Danci et al., 2015). Our previous work (Crisan et al., 2014) reveal the auxin-like effect of monoethanolamine salt of 4-aminobenzoic acid on Arabidopsis thaliana, suggesting that alkanolamine salts of substituted benzoic acids could be potential candidates for new plant growth regulators.

Taking into account the present and future prospects of Paulownia species, and the scarcity of researches on in vitro micropropagation of Paulownia shan tong, this study aims to investigate, for the first time, the effect of different alkanolamine salts of 4-nitrobenzoic acid as plant growth regulators on the callus induction and plant regeneration in Paulownia shan tong.

\section{MATERIALS AND METHODS}

The new compound, methylethanolamine 4-nitrobenzoate (4- $\mathrm{NO}_{2} \mathrm{BA}$ MMEA), diethanolamine 4-nitrobenzoate (4- $\mathrm{NO}_{2} \mathrm{BA}$ DEA) and triethanolamine 4-nitrobenzoate $\left(4-\mathrm{NO}_{2} \mathrm{BA}\right.$ TEA), were obtained by the Institute of Chemistry Timisoara of Romanian Academy, via proton exchange reaction, from 1:1 molar amounts of 4-nitrobenzoic acid and different alkanolamine, in acetone solvent. These compounds are based on biologically active components with low toxicity (Chicu et al., 2008). Alkanolamines are chosen as cations, because are less toxic comparatively with aliphatic amines and heterocyclic amine (Chicu, Herrmann and Berking, 2000), are cheap, commercially available and environmentally tolerable, some of them naturally occurring.

The internodes excised from healthy plant of Paulownia shan tong, collected from a culture of monitored fields were used as explants. They were cleaned in more steps: the material was washed in soapy water, rinsed with tap water, washed in chlorinated water and then the process was passed in sterile area, under laminar air flow hood conditions. The material was sterilized in ethanol in a concentration of $70 \%$ for 1 minute and $2 \% \mathrm{HgCl}_{2}$ for two minutes followed by five washes with sterile distilled water. Murashige and Skoog medium (MS) (Murashige and Skoog, 1962) supplemented with 3\% (Weight/Volume) sucrose and $0.6 \%(\mathrm{w} / \mathrm{v})$ agar was used as culture medium for the experiments. For micropropagation various plant growth regulators with different concentrations were studied, singly and in combinations, and the best response was obtained by a combination of BAP and GA3. After obtaining a stable culture, the MS medium was supplemented with the new synthesized compounds $\left(\mathrm{NO}_{2} \mathrm{BA}\right.$ MMEA, $\mathrm{NO}_{2} \mathrm{BA}$ DEA and $\mathrm{NO}_{2} \mathrm{BA}$ TEA) at two different concentrations each one ( $\mathrm{C} 1$ and $\mathrm{C} 2$ ), $0.5 \mathrm{mg} / \mathrm{L}$ and $1 \mathrm{mg} / \mathrm{L}$ and callus induction and plant regeneration were determined. The experimental variants were: MS0 - the control variant; $\mathrm{H} 1$ - MS with 4-NO ${ }_{2}$ BA MMEA; $\mathrm{H} 2$ - MS with 4-NO ${ }_{2}$ BA DEA; H3 - MS with 4-NO ${ }_{2}$ BA TEA and 2,4D - MS with 2,4-dichlorphenoxyacetic acid. All the cultures were kept in the growth room at $24^{\circ} \mathrm{C}$ under a $16 / 8 \mathrm{~h}$ light /dark regime. After four weeks, sprout length, number of internodes, number of leaves, number of ramifications and callus dimensions were measured, for each characteristic a number of 11 plants were measured for each cultivated variant (H1 - C1, C2; H2 - C1, C2; H3 - C1, C2; 2,4D - C1,C2; MS0). All the experiments were repeated three times. The average $(x)$ and standard deviation (SD) program were used to quantify the effect of different treatment. 


\section{RESULTS AND DISCUSSION}

In the present study, the effects of different alkanolamine salts of 4-nitrobenzoic acid on in vitro callus induction and plant regeneration in Paulownia shan tong were evaluated by employing internodes as explants. Nodal parts are considered one of the most suitable explants for in vitro improvements because these explants would preserve the genetic identity of the parent genotype. Data show that the induction of callus, differentiation and organogenesis are accomplished by differential application of compounds such as $\mathrm{NO}_{2} \mathrm{BA}$ MMEA, $\mathrm{NO}_{2} \mathrm{BA}$ DEA, $\mathrm{NO}_{2} \mathrm{BA}$ TEA and 2,4-D in the culture medium. Thus, the plantlets cultivated on MS with new alkanolamine salts exhibited a better morphogenic response for all compounds in comparison with the control (MS0), inducing the plant regeneration, callusing has not been observed at those cultivated variants. The sprout length, number of internodes, number of leaves and number of ramifications were the examined parties of the plants, for each characteristic a number of 11 plants were measured for each cultivated variant and the results are presented in Table 1. Although 2,4-D is a synthetic auxin, its role in inducing organogenesis and plant regeneration was not observed in our experiments. Efficacy of phytohormone 2,4-D has been reported for callus induction in Paulownia shan tong. Callus growth was not prominently increased and did not show significant variations (C1 - 1.075 \pm 0.417 ; C2 $-1.04 \pm 0.21$ ) along with the change of concentration.
The morphogenic response of the explants to akanolamine salts of 4-nitrobenzoic acid is related in Figure 1. Similar values for sprout length, better than control were observed in all cultivation variants with exogenous supply of salts, at 0.5 $\mathrm{mg} / \mathrm{L}$ concentration. But the maximum sprout length was noted for $\mathrm{H} 1$, at $1 \mathrm{mg} / \mathrm{L}$ concentration (Figure 1a). Regarding the number of internodes, best results were observed in $\mathrm{H} 1$ and $\mathrm{H} 2$ variants at $1 \mathrm{mg} / \mathrm{L}$ concentration (Figure $1 \mathrm{~b}$ ). The maximum number of leaves was observed in $\mathrm{H} 1$ variant at 1 $\mathrm{mg} / \mathrm{L}$ concentration (Figure 1c). The number of ramifications has the best results on $\mathrm{H} 1$ variant, $1 \mathrm{mg} / \mathrm{L}$ concentration and the minimum number of ramifications at $0.5 \mathrm{mg} / \mathrm{L}$ concentration (Figure 1c). Therefore, among the tested compounds, $\mathrm{NO}_{2}$ BA MMEA (1 mg/L) showed the best results for all analyzed parties.

In Figure 2 are represented the results in what regards callus induction, in this case there is a small difference between the two concentrations, better results were observed using $0.5 \mathrm{mg} / \mathrm{L}$ 2,4-D.

\section{CONCLUSIONS}

The present study concluded that culture medium MS supplemented with different alkanolamine salts ( $\mathrm{H} 1$ - H3) exhibited better morphogenesis at all tried concentrations, in comparison with synthetic auxin 2,4-D. Controlling in vitro morphogenesis should play important role at the applied level in developing new Paulownia cultivars and reducing the cost of micropropagation. Our study introduces new biological active compounds with low toxicity, efficient in inducing plant regenera-

Tab. 1. Effects of $\mathrm{NO}_{2} \mathrm{BA}$ MMEA, $\mathrm{NO}_{2} \mathrm{BA}$ DEA, $\mathrm{NO}_{2} \mathrm{BA}$ TEA and 2,4-D on callus induction and plant regeneration in Paulownia shan tong

\begin{tabular}{|c|c|c|c|c|c|c|}
\hline $\begin{array}{l}\text { Cutivation } \\
\text { variants }\end{array}$ & $\begin{array}{c}\text { Concentrations } \\
\mathrm{mg} / \mathrm{L}\end{array}$ & $\begin{array}{c}\mathrm{A}^{*}(\mathrm{~cm}) \\
x \pm \mathrm{SD} \\
\end{array}$ & $\begin{array}{c}\mathrm{B}^{*} \\
x \pm \mathrm{SD} \\
\end{array}$ & $\begin{array}{c}\mathrm{C}^{*} \\
x \pm \mathrm{SD} \\
\end{array}$ & $\begin{array}{c}\mathrm{D}^{*} \\
x \pm \mathrm{SD} \\
\end{array}$ & $\begin{array}{c}\mathrm{E}^{*}(\mathrm{~cm}) \\
x \pm \mathrm{SD} \\
\end{array}$ \\
\hline \multirow{2}{*}{ H1 } & 0.5 & $2.15 \pm 0.431$ & $3.5 \pm 0.848$ & $7.45 \pm 2.192$ & $1.1 \pm 0.282$ & \\
\hline & 1 & $2.31 \pm 0.433$ & $5.25 \pm 0.777$ & $9.85 \pm 2.192$ & $2 \pm 0$ & \\
\hline \multirow{2}{*}{$\mathrm{H} 2$} & 0.5 & $2.14 \pm 0.968$ & $4.06 \pm 1.329$ & $7.22 \pm 3.146$ & $1.47 \pm 0.226$ & \\
\hline & 1 & $2.01 \pm 0.777$ & $4.81 \pm 2.191$ & $8.16 \pm 3.62$ & $1.65 \pm 0.558$ & \\
\hline \multirow{2}{*}{ H3 } & 0.5 & $2.1 \pm 0.494$ & $4.34 \pm 1.103$ & $8.37 \pm 2.828$ & $1.46 \pm 0.049$ & \\
\hline & 1 & $1.85 \pm 0.445$ & $4.38 \pm 1.844$ & $6.68 \pm 1.322$ & $1.43 \pm 0$ & \\
\hline MS0 & & $1.59 \pm 0.275$ & $2.84 \pm 0.579$ & $5.43 \pm 0.968$ & $1.06 \pm 0$ & \\
\hline \multirow{2}{*}{$2,4 \mathrm{D}$} & 0.5 & & & & & $1.075 \pm 0.417$ \\
\hline & 1 & & & & & $1.04 \pm 0.21$ \\
\hline
\end{tabular}



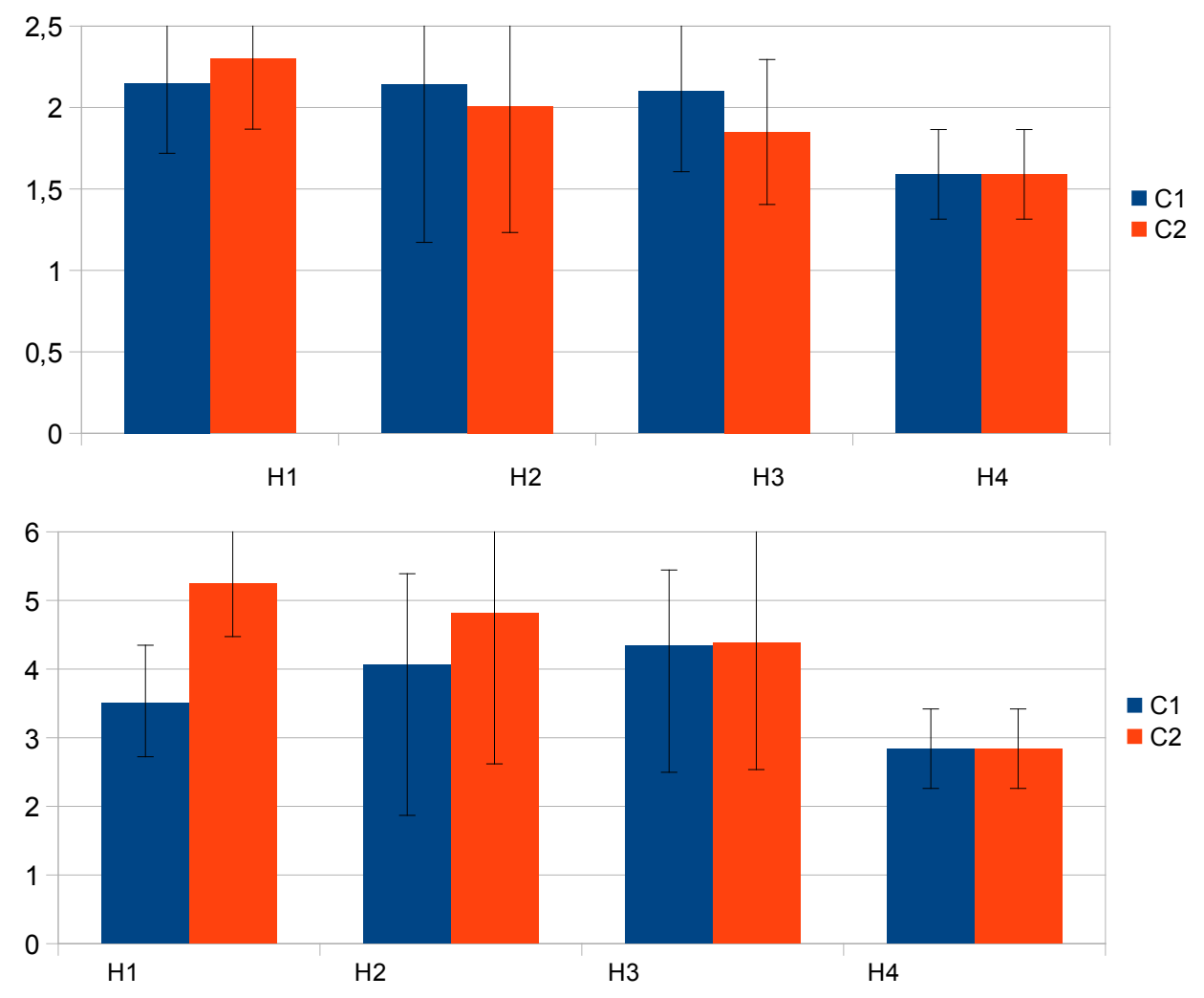

a.

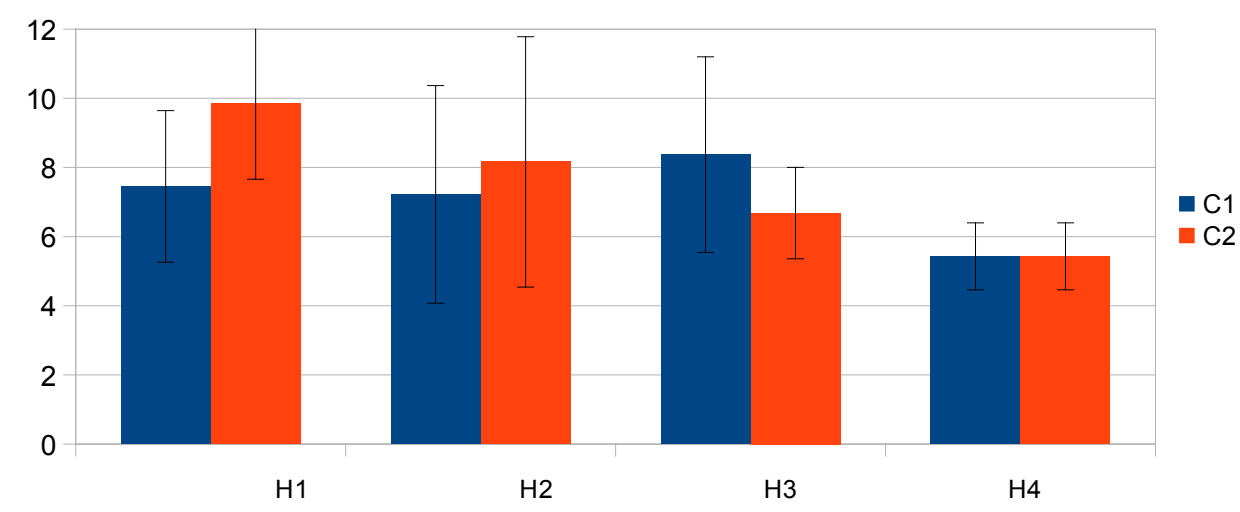

b.

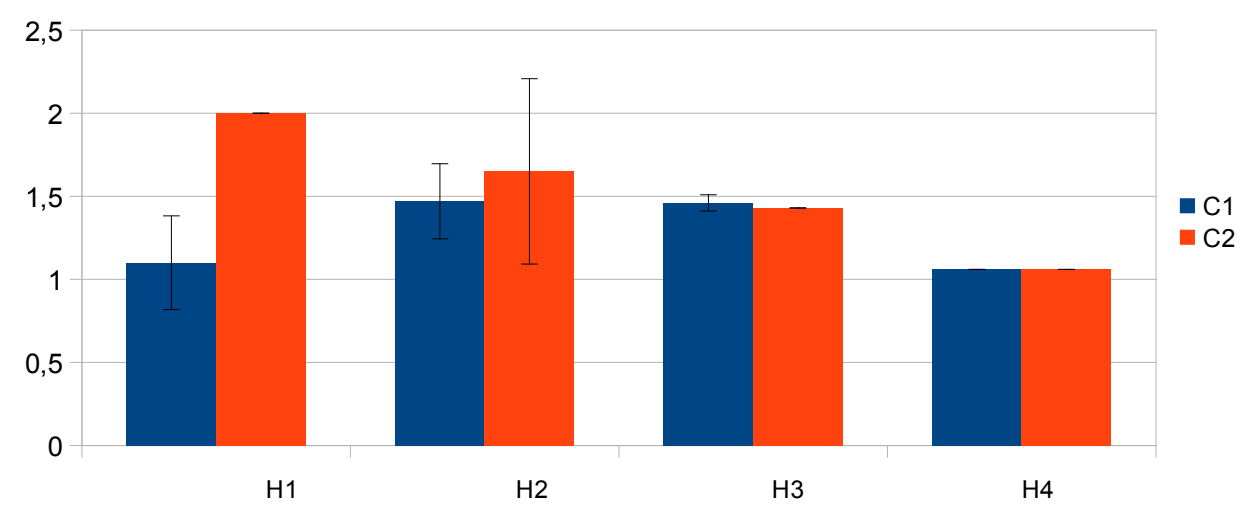

c.

d.

Figure 1. Effects of $\mathrm{NO}_{2} \mathrm{BA}$ MMEA, $\mathrm{NO}_{2} \mathrm{BA}$ DEA, $\mathrm{NO}_{2} \mathrm{BA}$ TEA in variants $\mathrm{H} 1-\mathrm{H} 3$ on induction of sprout length (a), numbers of internodes (b), number of leaves (c) and number of ramifications (d) 


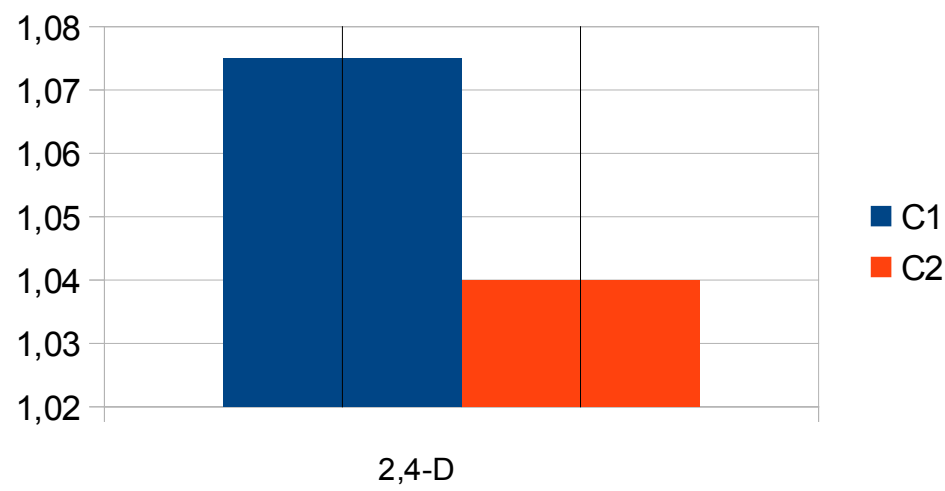

Figure 2. Effects of 2,4-D on callus induction

tion in Paulownia shan tong. Thus, H1-H3 culture variants present better results for growth of plant vegetable parties (sprout length, number of internodes, number of leaves and number of ramifications) in report to control. The best results for all analyzed parties were noted for $\mathrm{H} 1\left(\mathrm{NO}_{2} \mathrm{BA}\right.$ MMEA - $1 \mathrm{mg} / \mathrm{L}$ ). MS medium improved with 2,4D showed an induced callus development, with a small difference between the two concentrations in what regards callus dimensions. Therefore, these experimental results could contribute to optimize the culture treatments regarding morphological quality, induction of organogenesis, callus and plant regeneration.

\section{REFERENCES}

1. Akyildiz MH, Kol HS (2010). Some technological properties and uses of paulownia (Paulownia tomentosa Steud.) wood. J Environ Biol, 31:351-355.

2. Bergmann B, Moon H (1997). In vitro adventitious shoot production in Paulownia. Plant Cell Rep 16, 315.

3. Burger D, Lin L, Wu L (1985). Rapid micropropagation of Paulownia tomentosa. Hort Science, 20, 760

4. Chicu SA, Grozav M, Kurunczi L, Crisan M (2008). SAR for amine salts of carboxylic acids to Hydractinia echinata, Revista de Chimie, 59:582-587.

5. Chicu SA, Herrmann K, Berking S (2000). An approach to calculate the toxicity of simple organic molecules on the basis of QSAR analysis in Hydractinia echinata (Hydrozoa, Cnidaria). Quantit Struct-Activity Relation19, 227-236.

6. Crisan ME, Bourosh P, Maffei ME, Forni A, Pieraccini S, Sironi M, Chumakov YM (2014). Synthesis, Crystal Structure and
Biological Activity of 2-Hydroxyethylammonium Salt of p-Aminobenzoic Acid. Plos One, 9, e101892.

7. Danci M, Cretu I, Giancarla V, Luca R, Simina A (2015). Influence of plant growth regulator upon in vitro propagation of Paulownia sp. European Biotechnology 208, S113.

8. Feria MJ, García JC, Zamudio MAM, Gomide JL, Colodette JL, López F (2013). Kraft Pulping and Bleaching of Paulownia Sun Tzu 104® Wood. Cell Chem Technol 47:595-601.

9. Kiaei M (2012). Physical and Mechanical Properties of Paulownia Wood (Paulownia fortunei) in North Iran. Middle-East Journal of Research 11:964-968.

10. Mordhorst AP, Voerman KJ, Hartog MV, Meijer EA, van Went J, Koornneef M and De Vries SC (1998). Somatic embryogenesis in Arabidopsis thaliana is facilitated by mutations in genes repressing meristematic cell divisions. Genetics 149:549-563.

11. Murashige T, Skoog F (1962). A revised medium for rapid growth and bio-assays with tobacco tissue cultures. Physiol Plantarum 15:473-497.

12. Rao DC, Goh CJ, Kumar PP (1996). High frequency adventitious shoot regeneration of Paulownia ssp. cultured in vitro. Plant Cell Reports 16:204-209.

13. Zimmerman JL (1993). Somatic Embryogenesis: A Model for Early Development in Higher Plants. Plant Cell 5:14111423.

14. Yadav NK, Vaidya BN, Henderson K, Lee JF, Stewart WM (2013). A Review of Paulownia Biotechnology: A Short Rotation, Fast Growing Multipurpose Bioenergy Tree. American Journal of Plant Sciences 4:2070-2082.

15. https://www.stiriagricole.ro/banii-pot-creste-si-incopaci-plantatia-de-paulownia-asigura-un-profit-de-30000-de-euro-pe-hectar-26983.html 